\title{
MALE KESTREL SHARES INCUBATING DUTIES
}

ROY EVERITT, Box 53, Newdale, Manitoba. R0J 1J0

Two American Kestrels have nested in the southwest corner of the loft of our barn for several years, gaining entry through a split comer board. Last fall I remodelled the nest site, lining the cavity with a light, reflective material. The top was made with a hole for a camera lens. The late afternoon sun illuminated the nest cavity quite well. With a long remote release on my camera, I was able to photograph the birds on the nest and not disturb them. I left my camera on the nest for two days (26-27 May 1990) and took several photographs each afternoon. On getting my slides back, I was surprised to see both male and female share duties in incubating. These slides were taken before the eggs hatched. I consulted Birds of Canada (W.E. Godfrey. 1986. National Museum of Canada, Ottawa. 595 pp.) and there was no mention of both sexes sharing incubation duties. Is this normal?

Ed. Note: Male kestrels do less incubating than females. Eslich, Dobbin and Whegl, 1988. The birder's handbook. Simon and Schuster, New York. $785 \mathrm{pp}$.

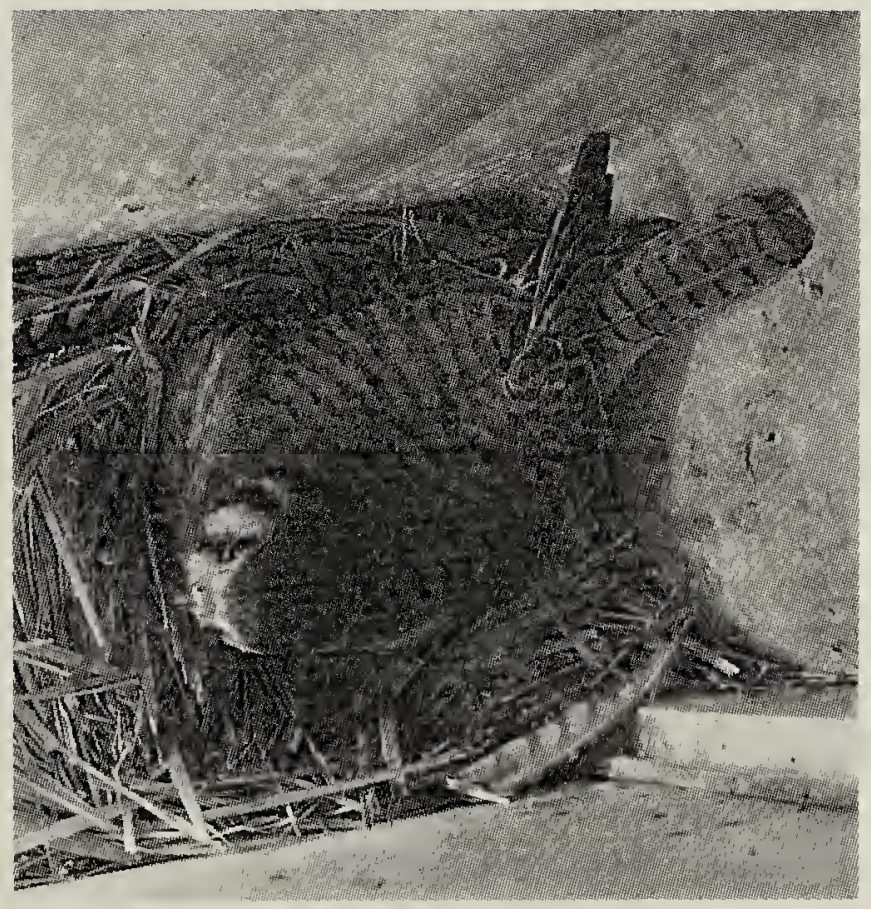

Male Kestrel

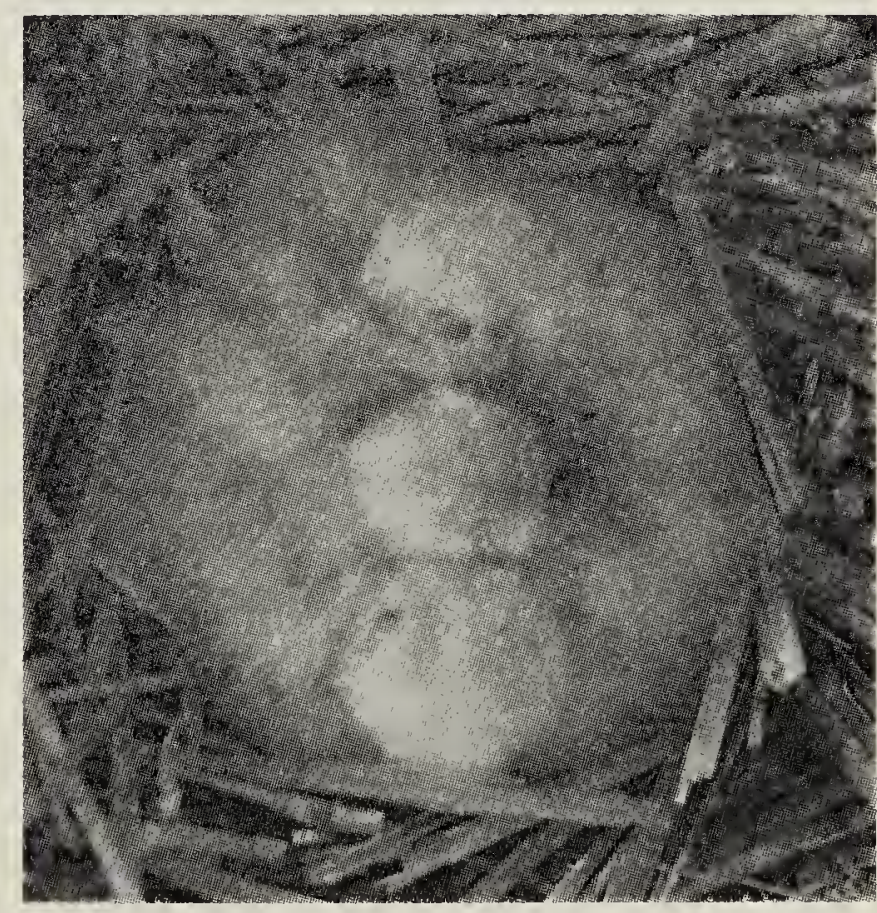

Kestrel chicks

Roy Everitt 